\title{
Humanização do parto como resgate cultural
}

\section{| ${ }^{1}$ Antônio Rodrigues Ferreira Júnior, ${ }^{2}$ Nelson Filice de Barros |}

' Programa de Pós-graduação em Saúde Coletiva da Universidade de Fortaleza (UNIFOR). Endereço eletrônico: junioruruoca@hotmail.com ${ }_{2}^{2}$ Programa de Pós-graduação em Saúde Coletiva da Universidade Estadual de Campinas (UNICAMP). Endereço eletrônico: nelfel@uol.com.br

O livro intitulado A Medicina Tradicional e os Sistemas Municipais de Saúde: humanização do parto sob o enfoque do patrimônio cultural, organizado por Daphne Rattner e Sonia Ferraz, publicado em português e espanhol pelo Conselho Nacional de Secretarias Municipais de Saúde (CONASEMS) em 2009, reúne textos oriundos de uma roda temática com profissionais de diversos países ocorrida em 2006 durante o XXII Congresso Nacional das Secretarias Municipais de Saúde.

Os objetivos do livro são: socializar experiências de incorporação das parteiras aos sistemas oficiais de saúde; resgatar essas importantes práticas para a humanização do cuidado nos partos e nascimentos; e comparar os processos dos diversos países, contribuindo para expressão das diversidades culturais e sociais intrínsecas a cada país da América Latina.

Nos seis capítulos que compõem o livro, são apresentadas experiências exitosas de diferentes países, principalmente da América Latina, relatando a inserção nos sistemas de saúde da prática milenar de acompanhamento obstétrico realizado por mulheres da própria comunidade. Em vários momentos, os autores traçam diagnósticos da situação atual do atendimento domiciliar do parto, explicitando as principais dificuldades para a manutenção e reconhecimento dessa prática, bem como sua inserção como atividade dos sistemas locais de saúde, em consonância com as normatizações delimitadas pelos órgãos competentes, visando à minoração das mortalidades materna e infantil. 
No segundo capítulo, que segue o capítulo de introdução, os autores discorrem acerca da vivência dessa prática em comunidades indígenas da Bolívia, denotando a preferência das mulheres pelo acompanhamento de parteiras nos seus domićlios, em detrimento dos serviços de saúde: consequência de variadas dificuldades de cunho geográfico, econômico e sociocultural. Há incentivo para que a mulher escolha seus acompanhantes e as práticas mais adequadas que podem facilitar o momento do parto, em antagonismo às ideias da sociedade moderna que priorizam a centralização do cuidado obstétrico no hospital, com aumento do aparato tecnológico e minimização da afetividade entre os participantes do processo.

O terceiro capítulo exemplifica ações brasileiras da gestão, nos âmbitos federal, estadual e municipal, para melhoria da atenção ao parto atendido por parteiras. São relatos detalhados de experimentações em três diferentes locais do país, especificando resultados positivos encontrados em suas implantações. Na gestão federal, há tentativa de reconhecimento público das parteiras como parceiras na atenção à saúde da comunidade, valorizando e potencializando seu trabalho junto ao Sistema Único de Saúde (SUS), como forma de aproveitar a liderança construída por elas na comunidade. $\mathrm{O}$ exemplo de gestão estadual mostra uma associação entre o serviço público de saúde e parteiras de comunidades indígenas em São Paulo, culminando com a organização de uma rede assistencial que busca respeitar a cultura dos povos e as normas institucionais de cuidado obstétrico. No âmbito municipal, é apresentada a vivência da integração entre a equipe de saúde e as parteiras tradicionais no município de Maués - AM, havendo a participação delas em todo o processo de planejamento, execução e avaliação das atividades.

O quarto capítulo do livro discorre sobre a atuação de três organizações não governamentais na atenção ao parto domiciliar: Cais do Parto, Grupo Curumim (brasileiras) e Grupo Ticime (mexicana). Nesse capítulo, é discutida a importância das atividades das parteiras - que agregam à tradição ancestral na atenção à mulher o uso de práticas integrativas e complementares - apesar das dificuldades de sua atuação por conta do corporativismo profissional e da hegemonia de correntes de pensamentos que menosprezam todo o conhecimento adquirido pelas comunidades ao longo do tempo, criando uma dicotomia com o conhecimento dito científico.

São explicitados variados problemas jurídicos que elas enfrentam, visto que os profissionais de saúde possuem suas associações para lhes defender quando algo não 
ocorre de forma satisfatória, ao contrário das parteiras, que atuam em comunidades

distantes, geralmente sem apoio oficial, sendo negligenciadas inclusive no acesso a mecanismos de defesa. As dificuldades na assistência obstétrica são grandes e disseminadas nos vários países latinoamericanos. Dentre elas, estão: baixa qualidade na assistência pré-natal; baixa resolubilidade dos serviços; inexistência de referência para complicações obstétricas e falta de reconhecimento oficial do trabalho da parteira. Em contraponto, a decisão política de base local de apoio ao trabalho das parteiras se coloca como importante meio para minimização dos problemas. É valido considerar que, nos municípios que tomaram para si a responsabilidade do gerenciamento das decisões referentes à temática, os desafios foram enfrentados, e mesmo superados, com maior facilidade.

No quinto capítulo, é apresentado um panorama da América Latina no que concerne às políticas de atenção ao parto, com ênfase nas práticas das parteiras. É explicitada a interface entre os sistemas públicos de saúde e as práticas tradicionais na atenção obstétrica na Argentina, Bolívia, Brasil, Chile, Costa Rica, Equador, Peru, Uruguai, Venezuela e Porto Rico. Vários projetos estão sendo implementados para a aceitação e o desenvolvimento dessas práticas, mas existem muitos empecilhos, embora sejam encontrados em todos os locais benefícios da inserção das parteiras como importante elemento na assistência ao binômio mãe-filho.

No último capítulo, há o relato de uma parteira da Holanda e de outra do Canadá enfocando como suas ações foram construídas e como são vistas pela sociedade de seus países. Os holandeses sempre tiveram o parto e o nascimento como algo natural, domiciliar, distante das práticas médicas hospitalares. Então, a maioria deles continua sendo realizado nas casas das mulheres, permanecendo como um importante acontecimento social. No Canadá, as parteiras estiveram marginalizadas por muito tempo, até ocorrer uma construção coletiva de defesa e resgate dos princípios defendidos por elas para a atenção obstétrica, embora tenha sido necessária a realização de estudos para comprovação científica de que a prática não era deletéria para a comunidade. Isso fez com que a profissão fosse regulamentada e com que a maioria dos partos fosse acompanhada nos centros de parto normal.

O livro faz, portanto, uma defesa do trabalho desenvolvido por parteiras, enfatizando a importância de suas práticas para manutenção das culturas dos povos 
de que fazem parte. Além disso, consegue mostrar de forma clara como a temática está inserida nas discussões oficiais dos governos de vários países, especialmente na América Latina, denotando a situação em que se encontram essas atividades em relação às políticas nacionais de atenção à saúde na área obstétrica.

Conclui-se, por fim, primeiro, que são várias as dificuldades para que as mulheres se tornem ativas no processo decisório que envolve suas vidas, em relação ao parto e nascimento. Segundo, que é grande a importância das parteiras tradicionais como agentes capazes de otimizar os cuidados dispensados à mulher e à criança durante o processo gravídico-puerperal. Terceiro, que as parteiras devem ser vistas como parceiras dos profissionais da saúde no âmbito dos sistemas locais de assistência obstétrica, agregando esforços para melhorar os cuidados realizados, reduzindo as mortalidades materna e infantil; não sendo necessária, portanto, a criação de falsas dicotomias entre o saber tradicional o saber científico.

\section{Referência}

RATTNER, D.; FERRAZ, S.T. (Org.) A Medicina Tradicional e os Sistemas Municipais de Saúde: humanização do parto sob o enfoque do patrimônio cultural. Brasília: Conasems; 2009. 103 p. 